\title{
Formation and Development of Effective Student Teams to Facilitate Team-Based Learning
}

\author{
Gretchen A. Mosher, Iowa State University, gamosher@iastate.edu
}

\begin{abstract}
The ability to work in an effective team has been identified by employers as a key skill for students entering the work force. Furthermore, a desire for active learning by both students and faculty has also increased the use of team-based learning. However, team-based learning also has its drawbacks - notably, managing conflict among team members, reconciling differing levels of effort by students, and the construction of a fair and effective method of assessment for teambased work. Highly developed and cohesive teams allow the focus of the classroom to be on engaged and transformative learning, yet previous research has focused mostly on the learning outcomes of such teams rather than on the formation and development processes.
\end{abstract}

The application of team-based learning in a third year, large enrollment course for engineering technology and engineering students will be discussed. Specifically, strategies used to select and develop teams and methods used to optimize the team-based learning processes will be highlighted. Student performance on key team-based learning activities and student evaluation of team-based learning will be shared. Suggestions for using team-based learning with engineering and engineering technology students will conclude the paper

\section{Team-Based Learning}

The ability to work effectively in teams has been identified as an essential skill for new employees to bring to the work environment upon graduation ${ }^{1,2}$. Furthermore, benefits to both faculty and students have been noted by those who have practiced team-based learning methods ${ }^{3}$. However, team-based learning also presents challenges to both students and instructors ${ }^{4}$. In addition to addressing both the benefits and challenges of team-based learning in engineering and engineering technology, this paper will discuss the application of the Michaelsen, Knight, and Fink ${ }^{5}$ method of team-based learning (TBL) to a course in total quality management. The process used to create and develop functional learning teams will also be a focus of the paper. Data on student performance and their feedback on the process will be included in the final portion of the paper.

\section{Benefits of Team-Based Learning}

Researchers have identified several benefits of TBL for students. These include: benefits to learning such the ability to tackle tasks of higher complexity, a stronger consideration of diverse perspectives, and a higher order of critical thinking ${ }^{2,3}$. Other benefits noted involve student social development. Researchers have observed greater engagement of students, enhanced abilities to collaborate effectively with student colleagues, and more highly developed civic values as a result of $\mathrm{TBL}^{6}$. In the science classroom, Carmichael ${ }^{6}$ noted that TBL not only 
enhanced both student learning and performance, but also energized the classroom and engaged the students in the field of study.

Benefits that are specific to the field of engineering have also been outlined by other researchers $^{8,9}$. According to Pascarella and Terenzini ${ }^{10}$ engineering benefits are based on the idea that group learning forces students to be more engaged in their learning and the greater the level of engagement noted, the higher the level of knowledge attainment and general cognitive development. According to Smith et $\mathrm{al}^{9}$, small group learning in large classes was found to have benefits which included enhanced critical thinking, promotion of social and emotional development, an increase in student appreciation of diversity, and a reduction in the number of students leaving the course.

Faculty benefits observed by researchers include the ability to see student performance and learning from a broader perspective. This occurs when faculty step away from the "chalk and talk" lecture model of presenting information. Giving students more ownership in their learning process removes faculty as the sole source of content information for student learners. When students are allowed to learn in teams, those who have high levels of knowledge can assist students with lower knowledge levels ${ }^{11}$. In a team-based learning environment, students must come to class with an understanding of basic procedures, facts, and information and then must apply these concepts to the situation or question posed in the classroom ${ }^{12}$. Team-based learning also releases faculty from the chore of "going over" a textbook point by point in class. Rather, students are required to complete a moderate amount of preparation before coming to class so that they can be successful with the course content as applied to the in-class activity or assessment $^{5}$. Finally, a major advantage to faculty who use TBL is the lower number of assignments to evaluate and grade ${ }^{3}$. This is especially true for large enrollment courses.

\section{Challenges of Team-Based Learning}

Although benefits to students and faculty have been noted across a variety of academic disciplines, TBL also has significant challenges. Disadvantages of TBL can be classified into three broad areas: learning barriers, social challenges, and faculty/instructor issues ${ }^{1,4}$.

Ashraf $^{4}$ suggests that TBL in the classroom does not always appropriately simulate the situation in the workplace and the result is that less motivated students may receive better grades and productive students receive lower grades, relative to the level of effort expended. He summarizes learning concerns such as lower quality work and stifled individuality as a result of group projects in the classroom. Ashraf ${ }^{4}$ also questions whether group projects result in students learning new skills, given that students often "divide and conquer" components of projects, working on the section of the project that they know best. Finally, Ashraf ${ }^{4}$ suggests that the efficiency with which the projects are completed is negatively impacted by group work, implying that the entire process can be poorly structured and inefficient, without clear benefits to learning.

Others have explored social challenges of teams working in a group, with the most of the discussion centering on "social loafing"1,12. Social loafing describes a situation where one or more team members do not perform their share of the group work, which in turn leaves a higher load for other team members ${ }^{2,12}$. The assignment of unrealistic group workloads and assigning 
each team member one specific role or task are also mentioned as antecedents to poor experiences with TBL. Logistical challenges to meeting outside of class, especially for students with other obligations, are also mentioned frequently as a barrier to student learning in teams ${ }^{4}$.

The final disadvantage focuses on the lack of instructor preparation for TBL. Peterson ${ }^{2}$ notes that just because teams are formed does not mean that the students have developed the critical skills needed to realize success when working with a team. Faculty intervention is needed to develop teamwork skills in student groups ${ }^{2}$, yet generally, little formal instruction is given by instructors on how to function as a group ${ }^{13}$. A final challenge to faculty when using group work is maintaining a fair and consistent grading system which rewards students proportionately based on the work performed ${ }^{3}$.

\section{Approach}

The team-based learning (TBL) approach developed by Michaelsen, Knight, and Fink ${ }^{5}$ attempts to combine the positive aspects of TBL while addressing the negative portions of team projects. The Michaelsen et al. ${ }^{5}$ method of TBL focuses a great amount of effort early in the course to the development of the team so that members interact well together, increasing their ability work together to complete complex course tasks. No specific roles are assigned for team members as all members are expected to work together toward the final goals. Teams are together for the entire term and do the majority of their work in class, but do have individual components that must be completed ahead of the class period. This allows the team members to have both individual and team-based accountability. The rapid feedback from both instructors and peer team members on the performance of both individual and team tasks are considered an essential component of the TBL process 5 . In this way, students are graded both individually and as a group by their instructor and by their fellow team members through a peer review process.

In class, students focus on four types of learning activities: understanding the course content, applying the content to problem solving or decision-making, learning effective teamwork skills, and understanding that the team approach will often result in a higher team grade than can be gained by students working independently ${ }^{5}$. In turn, the learning activities promote the four essential principles needed when implementing TBL. These include:

- Properly formed and managed teams

- Student accountability for both individual and group work

- Group assignments which promote learning and team development

- Frequent and timely feedback on student feedback

To ensure that the first principle is in place, several concepts must be promoted in group formation $^{5}$. First, to encourage a strong team, barriers that could negatively impact the group effectiveness and cohesiveness must be minimized. Examples of barriers that could limit the success of the team include pre-existing relationships between students or a lack of appropriate skills needed by team members. Building of cohesiveness works best from the "ground up", therefore; instructors should be purposeful in the team formation and should not allow students to self-select the teams ${ }^{1,3,5}$. 
To ensure teams are both large and diverse in terms of abilities and skills, specific factors are used to select teams. These factors allow each student the opportunity to make a significant contribution to the success of their group. The factors used to place students into groups may vary, depending on the goals of the instructor and the course. Student assets and liabilities are both considered when putting student teams together. Assets may include items such as full-time work experience, international exposure, previous course work, or other relevant factors. Liabilities could include limited previous coursework, limited English proficiency, or being a non-major in a major course. When student assets and liabilities are dispersed among the teams, groups have a tendency to be more effective ${ }^{5}$. Students generally cannot form their own diverse groups with their limited experience and knowledge, so the best scenario is to have the instructor form the groups, using pre-determined factors that will play an important role in the success of groups. Finally, Michaelsen et al. ${ }^{5}$ suggest that student groups stay together for the entire term, allowing them to refine the management and conflict resolution of the team to realize the best possible outcome in the course. When all of these factors are used in team formation, the likelihood of strong cohesiveness among teams is greater.

The second principle of TBL is student accountability ${ }^{5}$. To ensure individual accountability, students are assigned an individual Readiness Assessment Test (RAT) to complete. The RATs cover assigned reading or course preparation. Students take RATs individually first and submit them, and then complete an identical RAT with their teammates. As the group selects responses to the RAT, students are responsible for justifying and defending their opinions on their responses to the team. In this way, students are accountable to their peers while they revisit the course concepts, reiterating their learning of the material. A second way students demonstrate accountability to their team members is through peer evaluation. This gives team members the ability to assess their teammates for items such as individual preparation, attendance, and positive contributions to the team. The process appeals to students' motivation and provides an appropriate reward system for positive work in the course.

The third principle of TBL is that team assignments must encourage both learning and team development. For this reason, the development of activities well suited for teamwork is important, as other researchers have also noted ${ }^{1,3,5}$. Ideal team activities allow for course content to be applied, but do not involve long-term and complex endpoints (such as written reports). Furthermore, assignments which involve the analysis of complex issues, but that have a relatively simple response, also work well. This forces students to work together to answer the question, rather than divide up the work and come together to put together the final output, promoting team development and learning.

The final principle of TBL involves the feedback loop for students ${ }^{5}$. Rapid and frequent feedback contributes to learning and team development by allowing teams to see how close the knowledge of their teammates was to the intended response. If the group discounts the knowledge of a quieter student, and ends up with an incorrect response, the group may be more likely to include that student the next time. Likewise, the student with the correct answer who did not speak up in the first case may be more likely to give their response to the group because the score impacts not just the group, but the individuals in the group as well. In addition, students who missed the group activity can see what their absence from class cost them in terms of both knowledge and course points, promoting accountability to themselves as an individual as well as to their group. 
All four of the principles of TBL learning principles were applied in the spring 2013 offering of the course studied for this project. Quantitative and qualitative data were gathered on student performance and student evaluations of TBL in the course to answer the following questions:

1. Was student learning enhanced by using TBL strategies in Total Quality Management as measured by individual and team Readiness Assessment Tests?

2. Did students react positively to TBL teaching strategies as measured by student evaluations of the course?

3. Were conventional challenges of group learning effectively managed by the use of TBL strategies?

\section{Case Studied}

A modified version of Michaelsen et al's ${ }^{5}$ TBL method was administered to a convenience sample of 99 students who were enrolled in a third year course focusing on total quality management. The student population consisted of approximately $90 \%$ engineering technology students (split equally between agricultural systems technology and industrial technology) and approximately $10 \%$ engineering students. Students were placed into teams by the instructor on the first day of the course; using instructor-identified factors for course performance (Michaelsen et al. ${ }^{5}$ called these factors assets and liabilities). The factors are listed below.

\section{Figure 1. Factors Used in Team Formation}

1. Major outside of engineering technology

2. More than 2 consecutive years of professional-level work experience

3. Earned high school diploma outside of Iowa

4. Spent majority of childhood in city smaller than 25,000

5. Spent majority of childhood in city larger than 25,001

6. Major of AST (agricultural systems technology)

7. Major of I-TEC (industrial technology)

Factors were chosen based on the knowledge and background considered important to learning objectives of the course and on factors that could influence how students view the term "quality". Students who had a major outside the field of engineering technology allowed the instructor to separate engineers among the groups. Engineering students had a higher level of mathematics and generally had significantly different coursework background than students in engineering technology. Students with substantial professional work experience brought a higher understanding of quality management than conventional undergraduate students normally have, so students with this background were also split into multiple groups. Earning a high school diploma outside of Iowa was intended to separate students who had had different life experiences (including international experience) than the majority of students, who had been born and raised inside the state. The size of the city where the student was raised could impact their view of quality and their view of the fields of manufacturing and agriculture (both frequent case studies 
of interest in the course), so students were sorted based on these factors as well. Finally, to sort the remaining students, the two majors for whom the course was a requirement were split into separate groups.

Students were sorted into nineteen groups of five and one group of four and began working on team development activities the first day of class. All of the group work was completed in class, which helped prevent several of the logistical factors previously identified as a challenge in team-based work ${ }^{4}$. In addition to group problem sets and mini projects, students completed nongraded discussion questions and small group activities. As per the Michaelsen et al. ${ }^{5}$ TBL methodology, students also completed both individual and team Readiness Assessment Tests (RATs), with the team RATs completed in class.

Students completed nine individual RATs and nine team RATs and each was worth between 10 and 12 points each. The RATs generally covered concepts from the course and included a mix of application problems and conceptual questions. The points from individual and team RATs made up about one quarter of the final grade. In addition to the RATs, students took three individual exams with the same testing format as the RATs with a mixture of conceptual, application, and problem-based questions. Students also completed in-class group projects with their group members. In-class discussion activities were not graded, but were recorded for attendance tracking.

Groups were directed to manage their own attendance. If they were missing a group member, the group could decide whether the absent member should get credit for that activity, based on that member's pattern of contribution and attendance. If the other group members felt the missing member had a valid reason for missing class, they could include that person's name on the activity. If not, the group left the name of the absent group member off their final submission of the learning activity. The option of the group to make this decision choice was suggested by Michaelsen et $\mathrm{al}^{5}{ }^{5}$ in the interest of team development and accountability. In this way, team members are primarily accountable to their fellow team members on team performance rather than to their instructor.

\section{Results}

Although students did not greet the news that the course would use TBL positively, most students saw benefits in terms of both learning and performance in the course, based on their RAT scores and their self-reported learning. Quantitative data on the student performance are shown in Figure 2. Mean individual percentages for each of the nine RATs are shown in the diamond shaped points and the team mean score for each of the nine RATs are shown in the square shaped points in percentages. The individual mean scores are based on the mean individual score in each of the 20 teams, for a total $n$ of 99 . The mean percentage of points earned in team scores represent the mean team score across the 20 teams, for an $n$ of 20 . 
In all cases, the mean percentage earned by each team was significantly higher than the individual mean score of team members, as shown in Table 1. Some team members benefitted greatly from the support of their teammates and team activities, while those who had the highest individual scores on their team saw less of a gain. This was expected. Michaelsen et $\mathrm{al}^{5}$ observed that, in some cases, team scores out-performed even the highest scoring individual members. This pattern was not observed with these data, as seen in Figure 3.

Figure 2. Comparison of Individual Mean and Team Mean RAT Scores as Percentage of Total Points

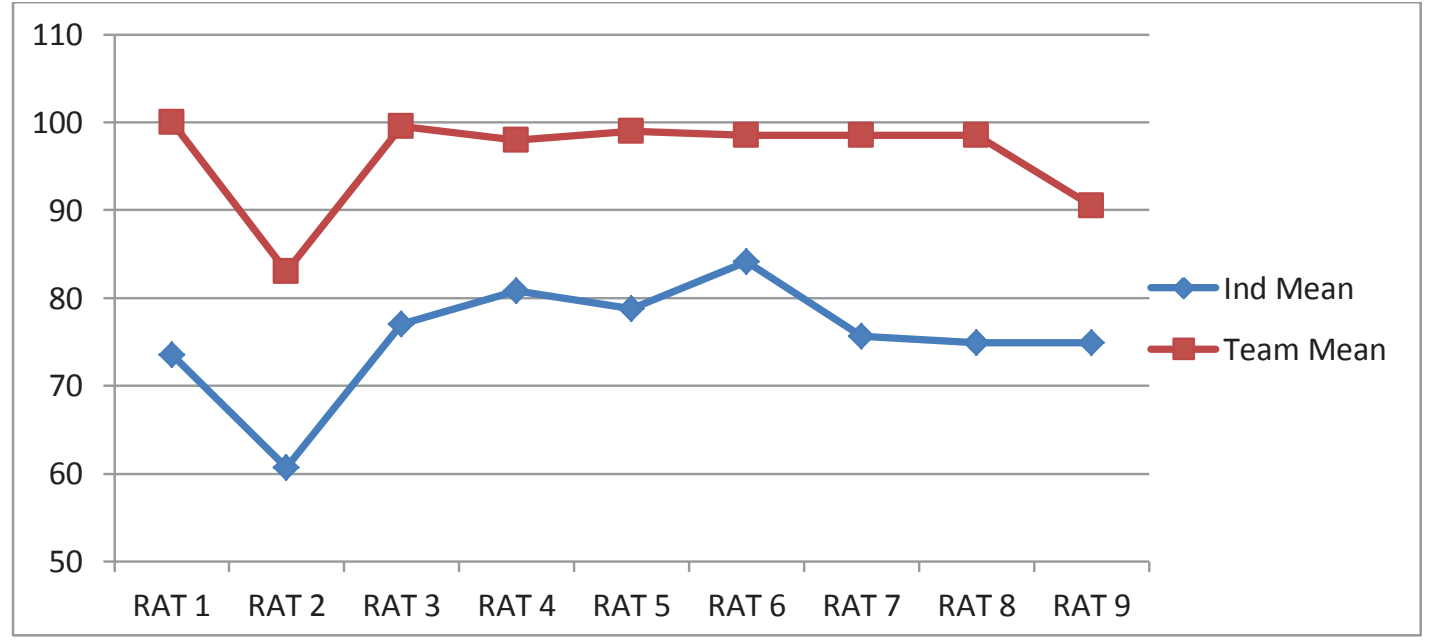

Figure 3 shows the mean individual high score across all 20 teams as compared with the mean team scores for the team RATs. The scores were very closely aligned with the exception of the final team RAT, which was given on the last day of class for the semester. This may have impacted the students' effort on the final team RAT.

Figure 3. Comparison of Individual Mean High Scores and Team Mean RAT Scores as Percentage of Total Points

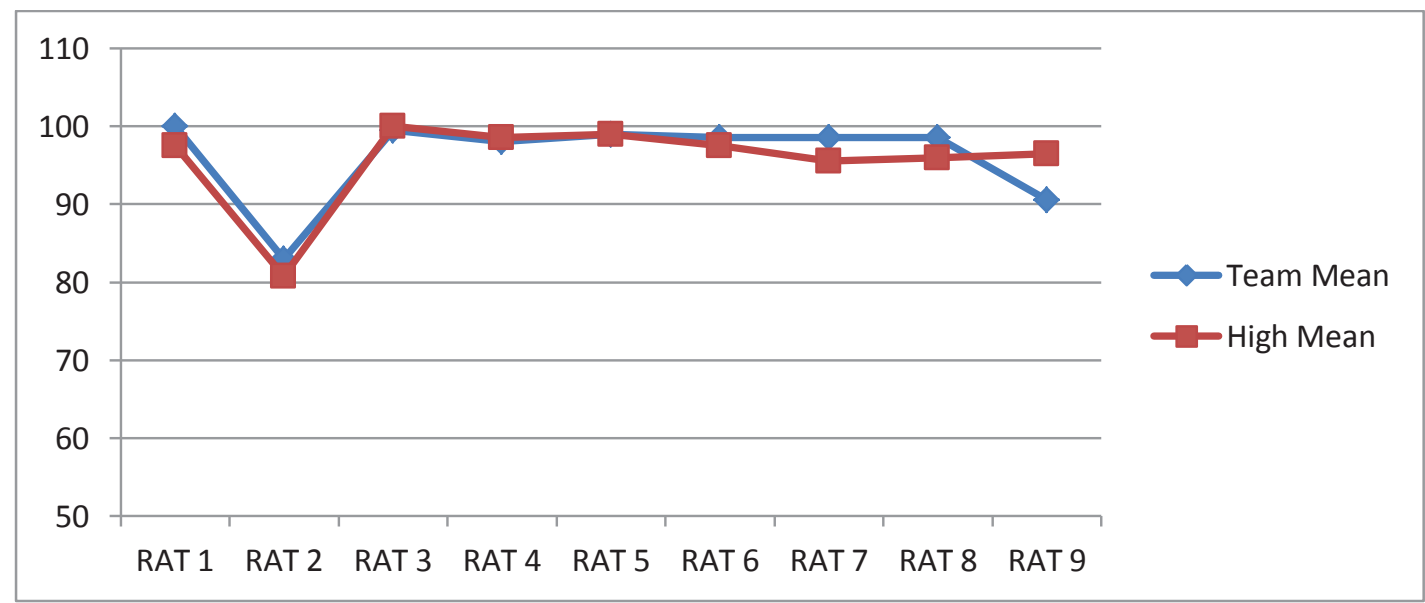


Paired comparison T-test results for individual mean scores and high scores for each group when compared with the mean team score are shown in Table 1. As observed in Table 1, no significant difference was noted between the scores of the highest group member and the team score. Although TBL activities did not significantly improve the scores of the highest scoring individuals, scores were not significantly lowered by their participation in TBL.

Table 1. T-Test Paired Comparisons of Individual Mean and High Scores and Mean Team Scores

\begin{tabular}{|c|c|c|c|c|}
\hline Variable & N & Mean score & Student t value & P-value \\
\hline Individual Mean Score & 9 & 7.71 & -14.44 & 0.000 \\
\cline { 1 - 3 } Team Mean Score & 9 & 9.81 & & \\
\hline Individual High Score & 9 & 9.75 & -0.58 & 0.575 \\
\cline { 1 - 3 } Team Mean Score & 9 & 9.81 & & \\
\hline
\end{tabular}

Student performance demonstrated what Michaelsen et al. $^{5}$ and others ${ }^{14,}{ }^{15}$ have previously reported. Generally, as a team, students perform at a higher level than they do individually. Although Michaelsen et al. ${ }^{5}$ have demonstrated that teams can out-perform even the highest performing individual on the team, the data for the total quality management course did not show this trend. Rather, the mean of the individual high score across all teams showed no significant difference from the mean of the team scores across all groups. This suggests that at the least, TBL can bring the knowledge of all team members up to the same level as the highest scoring member of each team. No significant difference was noted in the mean high individual scores across all 20 teams, suggesting that teams were sorted appropriately on ability, background, skills, and experience.

Students generally gave TBL teaching strategies positive feedback, with over $25 \%$ of students who completed the course evaluation specifically mentioning the RATs as being helpful to their learning. Fewer than $6 \%$ felt that RATs and TBL hindered their learning in the course. Although several students still were not big fans of TBL, many others felt working with their teams enhanced their learning in the course. Below are some of the comments students shared regarding how TBL helped them.

"the individual and team RATs and in-class exercises really helped me prepare for the exams ... I sometimes struggle with concepts in statistics and being able to do the RATs individually then work through them with my team really helped me better understand the material"

"I enjoyed the individual and team RATs. They helped drive across the main points each week ... I recommend keeping these for future classes"

"RATs really allowed me to understand the material that was presented" 
Not all comments were positive about the RATs. Some of the criticism (which is more personal opinion and less about the TBL method) is shown below.

"I didn't like the RATs - I forgot about them easily"

"Group work was not effective ... the RAT did not work for me and was usually done right before class as fast as I could"

The final research question addressed in this research was whether TBL could effectively manage some of the challenges of conventional group learning methods, notably free-riding and effective methods for grading groups. Student peer evaluations showed little difference across groups, but for the most part, the teams enjoyed the ability to control whether missing and underperforming group members earned points toward their grades. Students who came to the instructor about missing team RATs and other high-stakes class activities were directed to appeal to their group members. The group could make the choice whether to give their group member the benefit of the doubt on absences, but the pattern of class attendance was often a major factor in the group's choice. This accountability was also used in other course activities, including the group projects and in-class discussions.

The emphasis of the TBL methodology is class-based learning. When students were not in class, they could not earn points because the primary learning activities occurred in class, with the team. Therefore, when students were habitually absent, their grades were negatively impacted. Being recognized for positive behavior and for their level of work was something that students who attended and were engaged on a regular basis appreciated. This also lowered the number of complaints to the instructor from students on fellow group members who were not pulling their weight. Because the activities occurred in class, logistical concerns were not relevant to completing the projects and RATs. Consequently, issues about students who were unable to get together to complete the work were rare.

\section{Conclusions, Implications, and Limitations}

The experience using TBL in a mixed class consisting of engineering technology and engineering students was overwhelmingly a positive experience for the majority of the students and the instructor. Not only did student performance see modest gains with team-based work, students noted their enhanced learning in several cases. Using the TBL methodology developed by Michaelsen et al. $^{5}$ allowed the instructor to engage a large group of students without depending totally on lecture. Team-based learning also gave the students multiple opportunities to take advantage of the benefits of team learning without having to manage many of the challenges of working and learning in a group.

This work is subject to several key limitations. First, these data were collected from a convenience sample of students so their performance may not represent the performance of all courses of this type or of other engineering technology courses. Second, many factors impact 
how students perform in class. This research examined one potential factor - TBL - but others, such as group projects and in-class discussions, may have also been relevant to student performance. The focus of this work was the RATs and the learning observed through the completion of these activities in a team. The lack of a control course of non-TBL students limits the strength of the conclusions with this work. Finally, these data were collected over one semester. Different patterns may be seen as the size of the data pool is increased.

The process of TBL works very well for engineering and engineering technology courses in that students are required to be accountable both at an individual level and to their team. The discipline of engineering and engineering technology at its core requires students to master the material but to also apply the material and make connections ${ }^{16}$. Active engagement in the content is a second way that students learn the knowledge needed for expertise in engineering disciplines. One way to develop expertise is what Ambrose et al. ${ }^{17}$ refer to as "component" skills - a practice where one develops individual skills that can later be applied in more realistic and complex situations. Deliberate practice is needed to progress toward expertise in the engineering fields ${ }^{17}$ and TBL is one method of giving students the deliberate practice need to develop integration and application of component skills.

The use of TBL is recommended for engineering and engineering technology classrooms. Its use provides multiple benefits to student learning and student professional development. The ease of the methodology allows instructors to utilize the benefits of team work without having to manage many of the challenges of team-based class projects. The multiple components of TBL can be transitioned one piece at time when necessary to make the transfer to team-based learning easier for the instructor. For these reasons, TBL should be further explored by engineering educators who wish to further engage their students in both learning and professional skills.

\section{References}

1. Hansen, R.S. (2006). Benefits and problems with student teams: Suggestions for improving team projects. Journal of Education for Business, 82(1), 11-19.

2. Peterson, C.H. (2012). Building the emotional intelligence and effective functioning of student work groups: Evaluation of an instructional program. College Teaching, 60(3), 112-121.

3. Shimazoe, J. \& Aldrich, H. (2010). Group work can be gratifying: Understanding and overcoming resistance to cooperative learning. College Teaching, 58(2), 52-57.

4. Ashraf, M. (2004). A critical look at the use of group projects as a pedagogical tool. Journal of Education for Business, 79(4), 213-216. 
5. Michaelsen, L.K., Knight, A.B., \& Fink, L.D. (2004). Team-based learning: A transformative use of small groups in college teaching. Stylus Publishing: Sterling, VA.

6. Johnson, D.W., Johnson, R.T., \& Smith, K. (2007). The state of cooperative learning in postsecondary and professional settings. Educational Psychology Review, 19(1), 15-29.

7. Carmichael, J. (2009). Team-based learning enhances performance in introductory biology. Journal of College Science Teaching, 38(4), 54-61.

8. MacGregor, J. Cooper, J., Smith, K, \& Robinson, P. eds. (2000). Strategies for energizing large classes: From small groups to learning communities. New directions for teaching and learning, 81. Jossey-Bass, 2000.

9. Smith, K., Sheppard, S.D., Johnson, D.W. \& Johnson, R.T. (2005). Pedagogies of engagement: Classroom-based practices. Journal of Engineering Education, 94(1), 87101.

10. Pascarella, E.T. \& Terenzini, P.T. (1991). How College Affects Students: Finding and Insights from Twenty Years of Research. Jossey-Bass: San Francisco, CA.

11. Svinicki, M. \& McKeachie, W.J. (2011). McKeachie's Teaching Tips: Strategies, Research, and Theory for College and University Teachers. Wadsworth Cengage Learning: Belmont, CA.

12. Vasan, N.S., DeFouw, D.O. \& Compton, S. (2009). A survey of student perceptions of team-based learning in anatomy curriculum: Favorable views unrelated to grades. Anatomical Sciences Education, 2(4), 150-155.

13. Myers, S.A., Smith, N.A., Eidsness, M.A., Bogdan, L.M., Zackery, B.A., Thompson, M.R., Schoo, M.E., Johnson, A.N. (2009). Dealing with slackers in college classroom work groups. College Student Journal, 43(2), part b, 592-598.

14. Vasan, N.S.\& DeFouw, D. (2005). Team learning in a medical gross anatomy course. Medical Education, 39: 524.

15. Vasan, N.S., DeFouw, D.O. \& Holland, B.K. (2008). Modified use of team-based learning for effective delivery of medical gross anatomy and embryology. Anatomical Sciences Education, 1(1), 3-9. 
16. Litzinger, T.A., Lattuca, L.R., Hadgraft, R.G., \& Newstetter, W.C. (2011). Engineering education and the development of expertise. Journal of Engineering Education, 100(1), 123-150.

17. Ambrose, S.A., Bridges, M.W., DiPietro, M., Lovett, M.C. \& Norman, M.K. (2010). How Learning Works: Seven Research-based Principles for Smart Teaching. JosseyBass: San Francisco, CA. 